\title{
Cursos de Especialização e Aperfeiçoamento de Magistrados: suficiências e insuficiências
}

\author{
RAIMUNDO HELIO LEITE \\ Professor da Faculdade de Direito da Universidade Federal do Ceará \\ rhleite@terra.com.br \\ RUI VERLAINE OLIVEIRA MOREIRA \\ Professor da Faculdade de Direito da Universidade Federal do Ceará \\ rvomoreira@yahoo.com.br \\ CARMESINA RIBEIRO GURGEL \\ Professora da Faculdade de Educação da Universidade Federal do Piauí \\ carmesina@secrel.com.br
}

\begin{abstract}
Resumo
O objetivo deste artigo é mostrar a contribuição dos cursos de aperfeiçoamento e de especialização de magistrados, ministrados pela Escola Superior da Magistratura do Estado do Ceará (ESMEC), no período de 1995 a 2002. Utilizou-se uma entrevista semi-estruturada e o universo constituiu-se de 522 alunos que freqüentaram os cursos estudados, tendo sido retirada uma amostra de 60 participantes, proporcional ao tamanho da cada turma, representando $11,5 \%$ do universo. Foi utilizado o método fenomenológico de Edmund Husserl (1990), especialmente a redução fenomenológica que identificou a contribuição que os cursos deram para a formação dos magistrados. As falas apontam contribuição para a formação dos participantes, ao lado de insuficiências.
\end{abstract}

Palavras-chave: avaliação, magistrados, método fenomenológico, aperfeiçoamento profissional.

\section{Resumen}

El objetivo de este artículo es demostrar la contribución de los cursos de perfeccionamiento y de especialización de magistrados, ministrados por la Escuela Superior de Magistratura del Estado del Ceará (ESMEC), en el período de 1995 a 2002. Se utilizó una entrevista semiestructurada y el universo estuvo constituido por 522 alumnos que frecuentaron los cursos estudiados, retirándose una muestra de 60 participantes, proporcional al tamaño da cada clase, representando 11,5\% del universo. Se utilizó el método fenomenológico de Edmund Husserl (1990), especialmente la reducción fenomenológica que identificó la contribución que los cursos dieron a la formación de los magistrados. Las respuestas apuntan contribución a la formación de los participantes, al lado de insuficiencias.

Palabras-clave: evaluación, magistrados, método fenomenológico, perfeccionamiento profesional. 


\begin{abstract}
The aim of this article is to show the contribution of specialization and continuing education courses taught at the Magistrate School of the State of Ceará (ESMEC), between 1995 and 2002. A semi-structured interview was used with a universe of 522 students who had taken those courses. A sample consisting of 60 participants was extracted, in proportion to the size of each group. This sample represented $11.5 \%$ of the universe. Edmund Husserl's phenomenology method (1990) informed the research and the data analysis was carried out by phenomenological reduction and showed the contributions of the courses to the magistrates' education. The discourse in the interviews highlighted both the contributions to the participants' education as well as some shortcomings.
\end{abstract}

Key words: evaluation, magistrates, phenomenological method, professional improvement. 


\section{INTRODUÇÃO}

Este trabalho enfoca parte da descrição empírica dos dados coletados para a tese de doutorado que avaliou os cursos de aperfeiçoamento e especialização ofertados pela Escola Superior da Magistratura do Estado do Ceará (ESMEC), no período de 1995 e 2002 (Leite, 2004). Na elaboração da tese, esses dados serviram para a realização das etapas posteriores do método husserliano. Aqui far-se-á apenas uma descrição dos achados, caracterizando pontos fortes e fracos relatados pelas falas, no que diz respeito ao processo de ensino e aprendizagem e à formação geral dos magistrados que freqüentaram os cursos avaliados. Os depoentes foram informados que deveriam emitir as próprias opiniões acerca das questões, a fim de que se preservasse a natureza do método utilizado, ou seja, ir buscar na própria fonte os elementos a respeito da situação estudada.

A utilidade dos dados discutidos é inegável. Efetivamente, com a sistematização dos dados coletados e a aplicação de uma entrevista semiestruturada, foi possível reunir informações com alto grau de confiabilidade, uma vez que a participação foi espontânea e as informações colhidas de maneira impessoal. Praticamente, nenhum aspecto do processo de ensino e aprendizagem ficou fora das análises empreendidas, como se resumirá a seguir. Com efeito, foram evidenciados: a contribuição do professor para a aprendizagem e os pontos relativos à metodologia usada em sala de aula; a distribuição dos programas das disciplinas; o resultado positivo dos cursos para a formação técnica dos magistrados; a convivência em sala de aula; a relação teoria versus prática e a utilização dos equipamentos educacionais da ESMEC para a aprendizagem.

Nas reflexões finais, salienta-se a necessidade de que as escolas encarregadas pela formação de magistrados analisem esses dados e verifiquem em que grau eles refletem a realidade existente nessas escolas e, assim, questionem a formação atual de magistrados, bem como a natureza dos cursos que lhes são ofertados.

\section{PERCURSO METODOLÓGICO}

Este trabalho tem como eixo teórico a fenomenologia de Edmund Husserl (1859-1938), uma vez que se objetivou estudar a formação dos magistrados fenômeno, entendido por esse autor como aquilo que [...] significa efetivamente o que aparece, e [...] utiliza-se de preferência para o próprio aparecer (1990, p.35). Para tanto, utilizou-se a epoqué (dúvida, em grego) 
husserliana, na medida em que se põe entre parênteses os conhecimentos existentes sobre formação de magistrados, buscando apreender informações sobre esse tema com base nas falas dos próprios juízes.

Para estudar tal fenômeno, como ente resultante de atos cognoscitivos, o melhor caminho é trabalhar com a fenomenologia, pois ela é a

ciência dos fenômenos cognoscitivos neste duplo sentido: ciência do conhecimento como fenômenos (Erschauungen), manifestações, actos da consciência em que se exibem, se tornam conscientes, passivas ou activamente, estas e aquelas objectalidades; e, por outro lado, ciência destas objectalidades, enquanto si mesmas se exibem deste modo. (Husserl, 1990, p.3)

Aplicou-se uma entrevista semi-estuturada em 60 magistrados, $11,5 \%$ de um total de 522 que haviam freqüentado os cursos de formação da Escola Superior da Magistratura do Estado do Ceará (ESMEC), no período de 1995 a 2002. A participação foi espontânea e o tamanho da amostra levou em conta o critério da saturação, isto é, ao verificar que os ângulos do problema enfocado passaram a se repetir, recorrentemente, o pesquisador encerrou as gravações das entrevistas.

A pesquisa que originou a tese serviu-se dos três momentos do método: redução fenomenológica ${ }^{1}$, redução eidética (formação de um perfil) e redução transcendental, ou a busca final da essência do fenômeno (Husserl, 1992, 2001, 1950). Os dados aqui relatados caracterizam o primeiro momento, ou seja, a descrição e sistematização das falas dos magistrados sobre a formação que receberam nos cursos que freqüentaram.

Foi solicitado, aos participantes da amostra, que emitissem suas opiniões sobre a formação recebida nos cursos, para que ficasse bem caracterizado o [...] retorno às coisas [...] (Husserl, 1990, p.12). A partir das falas gravadas foram criadas as unidades de informação, contendo as falas com significados semelhantes.

\section{DISCUSSÃO E APRESENTAÇÃO DOS DADOS}

Os dados apresentados a seguir mostram a contribuição dada pelos cursos para o desempenho da carreira de juiz. Mostram a importância do

\footnotetext{
1 É a primeira etapa do método fenomenológico husserliano que exige que o pesquisador não leve para a pesquisa de campo concepções prévias, de natureza prática ou teórica. Ele deve se despojar das visões existentes sobre o problema que vai pesquisar, e se concentrar no que vai parecer do seu trabalho de campo. Somente depois de coletar seus dados buscará teorias que os expliquem. 162

Estudos em Avaliação Educacional, v. 17, n. 35, set./dez. 2006
} 
professor para a aprendizagem, a metodologia adotada em sala de aula, a convivência em sala de aula, a insuficiência da prática desenvolvida em sala de aula, a utilização de conhecimentos não jurídicos, a inexistência de conteúdos para a formação ética do magistrado, e os conteúdos relacionados com a formação técnica dos juízes.

É relevante destacar que os depoimentos citados constituem unidades de informação uma vez que resumem idéias semelhantes constantes de outras falas. As unidades de informação não foram quantificadas em virtude de o método empregado ser qualitativo por natureza.

\subsection{Elementos Ingredientes do Processo Pedagógico}

Pesquisas educacionais mostram que a aprendizagem, em todos os níveis de ensino, depende de fatores associados ao professor, ao aluno, à metodologia adotada e às condições físicas existentes no ambiente escolar. A compreensão dos alunos sobre o papel que cada um desses elementos exerceu nos cursos será apresentada a seguir.

\section{Contribuição do professor para a aprendizagem}

A importância do papel que o professor desempenha na aprendizagem varia quanto ao grau e à função, de acordo com a teoria de aprendizagem adotada por quem analisa esse papel. $\mathrm{O}$ relacionamento dele com os alunos, no entanto, ocupa posição relevante em qualquer dessas abordagens. Os depoimentos avaliam a qualidade e o relacionamento entre professores e alunos: [...] os professores eram bem preparados e mantinham um bom relacionamento com os alunos (D29, D50, D44, D49).

Os professores, vindos de outros Estados, eram encarregados de ministrar os Seminários Especiais sobre temas considerados importantes para o curso. Os temas desses seminários enfocaram as reformas do Código de Processo Civil e do Código de Processo Penal. Nem todos os entrevistados, porém, concordam com as opiniões anteriores, como se pode ver neste depoimento:

[...] outra crítica que faço é que, durante os seminários, saíamos encantados com as palestras de alguns dos conferencistas. Observei, todavia, que se tratava de uma coisa mecânica. Parecia um teatro, a pessoa decorava aquilo e repetia tal e qual. Cito apenas um caso de um deles que falou na ESMEC e repetiu a mesma coisa na UFC. (D42) 
Apesar da crítica desse entrevistado, a quase totalidade deles emitiu opinião positiva sobre a qualidade dos professores do quadro permanente dos cursos, bem como dos professores visitantes. Ademais, não é de se esperar que um conferencista venha falar a respeito de um mesmo tema, num curto espaço de tempo, com duas ou mais palestras prontas. Aqui se vislumbra o grau de exigência do público que freqüenta a ESMEC; é como se desejassem exclusividade até em relação aos professores convidados, haja vista que, verificando a lista desses palestrantes, vêem-se nomes da mais alta relevância no cenário jurídico brasileiro. Homens e mulheres requisitados no exterior para conferências foram trazidos a Fortaleza, motivo pelo qual observações desta natureza causam espécie.

Os alunos que participaram dos cursos ministrados avaliaram também, de forma positiva, a competência profissional e técnica dos professores, o que era de esperar, até porque o corpo docente é o mesmo, com poucas substituições. Um depoente atesta que [...] os professores são muito estudiosos (D01), enquanto outros declaram que [...] todos os professores serem [são] excelentes (D11, D08).

Esses depoimentos mostram que a opinião dos participantes dos cursos de aperfeiçoamento e especialização coincidem em relação à avaliação dos professores, as quais estão situadas entre os conceitos excelente e bom, envolvendo conteúdo e metodologia de ensino.

\section{Metodologia adotada pelos professores em sala de aula}

A metodologia mais usada nos cursos de bacharelado em Direito é a aula expositiva. No caso dos cursos em estudo, o fato mais marcante desse aspecto foi a falta de diversidade de métodos usados pelos professores em suas aulas. Alguns depoimentos registram esse fato.

[...] as aulas eram do tipo das lecionadas em faculdade. Os professores ficavam falando; às vezes levavam um caso para ser estudado. Havia outros que levavam questionários, que se ficava debatendo com os colegas; dependia de cada professor. Tinha uns que ficavam dando aquela aula teórica, expositiva, enquanto outros traziam textos. (D21)

Das entrevistas realizadas, colhe-se um dado interessante a respeito do assunto: a importância que os participantes dão ao professor que alia a teoria à prática forense, a ponto de acharem tão ou mais importantes as experiências práticas trocadas em sala, sob a orientação do professor, do que as lições teóricas a respeito dos vários assuntos. 
Quanto às críticas em relação à didática desenvolvida em sala, ressalte-se que vários alunos da ESMEC são professores de alguma faculdade em Fortaleza, portanto, carregam a experiência da cátedra e, por isso, talvez, o nível de exigência seja maior.

As aulas eram expositivas e pouco profundas e os conteúdos sofreram desvios em relação aos seus objetivos, na avaliação desses dois depoentes: [...] as exposições não foram uma coisa profunda. Achei que foram muito superficiais. Até que, pra mim, não houve muita diferença da faculdade (D30). [...] entendo que alguns professores não deveriam ensinar, apesar de poderem até ter muita teoria, mas, na hora de repassar, ficam contando casos que tiveram e era só isso que acontecia na aula (D26).

$\mathrm{O}$ depoimento a seguir mostra que houve estudo em grupo dos temas apresentados por determinados professores.

[...] mas houve uma cadeira em que o professor colocou os alunos para repassarem para a turma o que eles haviam aprendido no estudo em grupo. Cada grupo discutia e apresentava os resultados para os outros grupos. (D29)

O depoimento que se segue confirma que houve debates e aponta na mesma direção do anterior, ao analisar o nível de participação dos alunos em sala de aula, ressalvando que [...] as aulas poderiam ser dadas de uma maneira que pudesse explorar mais a participação direta do aluno do curso nas exposições. Houve debates, mas de uma maneira muito restrita (D23).

Um depoimento configura uma situação em que a variedade de métodos não propiciava a participação mais efetiva dos alunos, porque [...] o método era muito variado [...] só achei [...] que ficava muita coisa sem se debater (D45).

Existem, atualmente, diversos recursos pedagógicos que podem ser utilizados em sala de aula. O giz e o quadro negro continuam disponíveis, mas a estes podem ser adicionados outros, especialmente, os incorporados pelo uso das tecnologias de informação, que não foram empregados nos cursos avaliados. Não se trata de usar simplesmente meios pedagógicos modernos, mas o seu emprego poderia revelar certa modernidade na pedagogia empregada.

Embora os depoimentos não sejam de alunos de uma mesma turma, o quadro geral que se quer traçar aqui não fica prejudicado, por dois motivos: primeiro, o interesse neste estudo é esboçar um quadro geral das metodologias usadas nas várias disciplinas lecionadas, no período estudado, e não em cada uma delas individualmente; segundo, as mudanças ocorridas no corpo docente foram muito pequenas, o que 
assegura, muito provavelmente, que os elementos revelados estejam presentes em todas as disciplinas.

Os cursos ministrados apresentam, igualmente, uma variedade semelhante aos cursos do período anterior, no que diz respeito aos métodos utilizados pelos professores pois [...] cada professor tem [tinha] um método diferente (D03, D02). As aulas também eram expositivas, porque [...] há [havia] professores que gostam [gostavam] mais de se sentar e falar [...] (D03, D13). Muitos outros depoimentos mencionaram esse tema.

A diversidade de métodos era acompanhada, segundo o próximo depoimento, pela falta de programação e continuidade dos conteúdos, isto é, dois ingredientes fundamentais para a aprendizagem deixaram de ser utilizados.

[...] o professor chegava, não tinha um tempo certo para a aula [...] acho que faltou, lá, uma certa programação. Por exemplo, o responsável pelo curso chegar e dizer: "professor, você vai dar tantas aulas sobre esse assunto", e dentro desse assunto ele vai enfocar tal conteúdo, seguindo tal metodologia, como num programa normal de disciplina. (D03)

Apesar da utilização de aulas expositivas, os professores proporcionavam discussões e debates, como enfatiza esse depoente: $[. .]$. aula expositiva é bastante utilizada, mas com abertura para o debate e também para colocação de perguntas (D09). Por sua vez, a prática do debate era insuficiente, como declara o mesmo entrevistado: [...] acho que deveriam se intensificar os debates [...] (D09).

Os depoimentos não deixam a menor dúvida quanto à variedade de métodos de ensino utilizados pelos professores. Essa diversidade não é ruim. Nota-se, todavia, que as variações metodológicas, como o debate e a participação dos alunos em sala de aula, não se realizavam do modo como deveriam ser feitos, isto é, com roteiros de perguntas orientadoras, por exemplo, e o tempo dedicado aos debates também foi insuficiente. Em resumo, não havia uma programação adequada, de modo que fosse destinado a cada atividade o tempo necessário para que a sua execução se tornasse eficaz, sob o ponto de vista pedagógico.

\section{Distribuição dos programas pelos professores}

O programa de uma disciplina representa o roteiro e o guia das atividades que serão desenvolvidas, isto é, a indicação dos conteúdos, a metodologia que será utilizada e as formas de avaliação da aprendizagem. Trata-se, portanto, de elemento indispensável para o aluno e para o 
professor. Ele pode ser visto como uma carta de intenções sem a qual o professor não irá muito longe em sua disposição de ensinar algum conteúdo. O desconhecimento dessa "carta de intenções", pelos alunos, é algo parecido com o de começar um jogo sem saber as regras que o regem, ou pilotar um avião sem conhecer o plano de vôo e as regras de navegação aérea.

Alguns depoimentos fazem referência à entrega dos programas pelos professores das disciplinas, pois dois entrevistados afirmam: [...] os professores apresentavam os programas das disciplinas. Com os programas, vinha a bibliografia com a relação dos livros que o aluno poderia até comprar para estudar (D21, D23). Alguns depoentes, talvez em razão do tempo decorrido desde a realização dos cursos, não se lembravam se esse recurso didático havia sido empregado.

Além da distribuição dos programas, a sua execução é mais importante para a aprendizagem. $\mathrm{O}$ encadeamento lógico das unidades, a especificação dos objetivos de cada unidade, a indicação e o uso efetivo das estratégias de ensino e de avaliação, dentre outros, são requisitos indispensáveis a um bom programa de disciplina. Parece que esses requisitos nem sempre foram preenchidos, uma vez que [...] alguns professores cumpriam um programa. Outros davam as aulas; não tinha, assim, um raciocinio encadeado. Um dia era uma coisa, outro dia, era outra. Isto é, eram desenvolvidos temas aparentemente soltos, sem um encadeamento lógico (D26).

Um depoimento apenas menciona, de forma explícita, além da distribuição de programas, o uso de apostilas como recurso pedagógico auxiliar: [...] havia apostilas, isto é, dependia de cada professor; ou seja, cada um adotava um modo diferente com relação a livros e bibliografia (D29).

Embora alguns depoimentos tenham feito referência à entrega dos programas das disciplinas dos cursos ministrados, apenas um foi explícito quanto à sua apresentação: [...] os professores apresentaram os programas das disciplinas (D07).

Há reclamações sobre a carga horária dos programas, sobre a falta de cumprimento dos conteúdos, da sua extensão, mas não se menciona se esses programas foram discutidos com os alunos e se dessa discussão resultou algum tipo de mudança ou adaptação às suas necessidades. Um depoente reclama da extensão dos programas: [...] não tinha como esgotar todo o programa, porque ou o conteúdo era muito extenso ou porque a carga horária era pequena (D07).

O ordenamento lógico das unidades de um programa é fator indispensável para que o seu desenvolvimento se faça de modo que contribua para a aprendizagem dos alunos. Um depoimento mostra que, pelo menos em uma das disciplinas, isso não ocorreu: [...] não havia unidade 
nem seqüência lógica das matérias. Nós começamos a ver a parte constitucional e depois a parte processual (D02).

As principais reclamações neste tópico dizem respeito à falta de encadeamento e execução lógica dos programas das disciplinas, algo preocupante sob o ponto de vista da aprendizagem. É de pouca valia a distribuição dos programas das disciplinas, se eles não são implementados de forma a dar ao aluno uma perspectiva de continuidade e encadeamento dos assuntos.

\section{Convivência em sala de aula}

O relacionamento entre os colegas é o motivo mais apontado pelos entrevistados em relação ao aspecto de vivência humana experienciada durante o curso e digna de ser mencionada. Foram unânimes ao apontar a cordialidade existente e até a amizade desenvolvida no grupo e que é mantida até o presente.

[...] a convivência em sala de aula era boa. Como sempre, havia os grupos que se formavam na classe, mas a convivência era muito boa. Logo, a grande maioria era constituída de juízes. Conheci alguns colegas nessa época e, desde então, ainda permaneço em contato com eles. (D23, D21)

Apesar de a convivência em sala de aula ser boa, a formação de grupos é vista por outra entrevistada como algo difícil de ocorrer entre os magistrados. É interessante observar que a depoente é magistrada e sua opinião pode refletir relacionamentos que ocorreram fora de sala de aula.

[...] o pessoal com quem é mais difícil de se fazer amizade é o grupo dos magistrados. Há um egoísmo muito grande entre os colegas da magistratura. Não tem amizade entre nós, cada um vê o outro como um inimigo. Não sei explicar a razão disso. (D21)

Segundo esse depoimento, há uma diversidade de profissionais na turma. O depoimento deixa perceber, claramente, que havia integração entre as pessoas, sendo o grupo dos magistrados o que tinha mais dificuldade para se integrar.

De acordo com o depoimento a seguir, havia eqüidade no que diz respeito à participação dos alunos nas discussões em sala de aula.

[...] não havia predominância da opinião dos juízes sobre os outros profissionais. Pelo contrário, as pessoas que mais falavam eram os advogados e outros profissionais do Direito que estavam fazendo o curso. Tudo dependia da personalidade de cada um [...]. (D26, D21) 
Outro depoente discorda dessa visão participativa de todos os alunos:

[...] sentia, como sinto, uma timidez grande por parte dos advogados. Alguns porque são novos e estão convivendo com juízes que, em tese, têm uma idade mais avançada do que rapazes recém-saídos da universidade, que estão absorvendo os primeiros casos da profissão. Sinto, portanto, que havia uma timidez na interação dos advogados com os juízes. (D27)

Há, aparentemente, discrepância entre as duas opiniões acerca da atuação dos advogados nesse curso. Porém, ao ler com atenção o segundo depoimento, observa-se que o autor fala em [...] timidez na interação dos advogados com os juízes [...]. Isso significa que, na sua visão, os advogados não se aproximavam muito dos juízes; entretanto, não se pode concluir que eles não participassem, em pé de igualdade, dos debates em sala de aula. Embora os cursos se destinassem prioritariamente aos magistrados e fossem lecionados numa escola superior de magistratura, é difícil acreditar que os outros profissionais do Direito perdessem sua identidade essencial no exercício do contraditório.

No conjunto, as entrevistas revelam a inexistência de opinião unânime sobre o papel desempenhado pela convivência em sala de aula para a formação profissional: [...] a convivência com os colegas era muito boa. Naquela época [1995], não era magistrado, então não havia integração. Os magistrados ficavam lá, os bacharéis cá (D11). Em 2002, porém, esse mesmo entrevistado observa um clima diferente no relacionamento da turma: [...] nesta oportunidade, como magistrado, tenho notado que há um relacionamento mais estreito entre os colegas e isto tem sido válido (D11). Houve integração também nos cursos ministrados em 2000:

[...] a turma era assim, bem amiga. Era interessante que os alunos eram juizes, advogados, profissionais liberais e profissionais do Banco do Nordeste do Brasil; [...] então foi muito interessante essa convivência com pessoas de outra classe de operador do Direito, que não juizes, como advogados e profissionais liberais. (D06)

Enquanto a diversificação dos participantes é vista, por alguns, como positiva para o ensino, outros não têm a mesma opinião e consideram a convivência em sala de aula difícil: [...] o grande problema hoje, na ESMEC, é você misturar juiz e advogado numa mesma sala de aula (D02). O depoimento a seguir aponta alguns motivos para que essa convivência não seja boa:

[...] juiz da Capital não gosta, porque sabe que vai se deparar lá com a maioria dos advogados que estão todo dia nas nossas varas solicitando até favores impossíveis 
de serem atendidos e, ao chegar numa sala de aula, as nossas fraquezas e as nossas fragilidades, evidentemente, são expostas [...]. (D02)

Outro depoente, ao contrário, vê como positiva a presença de juízes em sala de aula, pois assegura que, como advogado, [...] é bom você saber como os magistrados estão pensando, como é que o Judiciário está funcionando (D01). O trecho [...] é bom saber como os magistrados estão pensando [...] mostra bem a realidade apontada pela entrevista anterior. Questiona-se: é bom que os pensamentos dos juízes sejam conhecidos no processo por meio das decisões e sentenças ou numa sala de aula? Neste trabalho, não cabe resposta à indagação, mas deve ser motivo de preocupação para a administração da ESMEC, pois as posições divergentes adotadas pelos juízes são importantes e devem servir para reflexão.

No conjunto, as entrevistas revelam que é salutar e enriquecedor, para a formação profissional, a integração entre os colegas e a presença, no mesmo espaço pedagógico, de pessoas com experiências diferentes, que trabalham no mesmo ramo de conhecimento, embora, em certos momentos, os juízes tentem impor suas opiniões, como destaca um depoente: [...] convivência tem sido muito boa. Agora, às vezes, percebe-se que os juízes querem fazer prevalecer suas opiniões, até mesmo diante do professor que tem estudado aquela disciplina (D05).

\section{Insuficiência da prática desenvolvida em sala de aula}

Embora se trate de alunos com larga experiência prática, o exercício da profissão os leva a enfrentar casos que envolvem grandes dificuldades no seu dia-a-dia, o que exige um exercício constante de aquisição de conhecimentos, visando a renovar e ampliar suas competências práticas na Ciência Jurídica.

O conhecimento da legislação é uma condição necessária, mas não suficiente, para o desempenho da função de um magistrado, uma vez que o problema concreto que ele tem de enfrentar é a aplicação dessa legislação em cada caso que lhe é apresentado. Cada situação conflituosa tem nuanças próprias, que necessitam ser sempre desveladas para que o magistrado ou qualquer aplicador da lei possa descobrir a propriedade e a pertinência da aplicação de determinada legislação. Em razão disso, a prática é muito importante para a formação do profissional do Direito, em especial o juiz. É por meio dela que o magistrado exercita a escolha e o uso apropriado da legislação no caso concreto. A prática, porém, não foi explorada como muitos os alunos esperavam. 
[...] no curso da ESMEC, não vi nada prático. Em termos de profissão, de aperfeiçoamento, de prático, nada obtive. Por ter pouco tempo na magistratura, buscava mais essa parte prática. Tinha me formado há pouco tempo, tinha feito curso de especialização; então, em termos de teoria, estava até afiada, vamos dizer assim; em termos teóricos, era como se estivesse revendo os conteúdos, até com menor profundidade. (D26)

Admitem-se aqui perguntas para reflexão: qual o objetivo real dos cursos de especialização da ESMEC? Os cursos ministrados na ESMEC têm por objetivo melhorar a formação de juízes, promotores e procuradores ou preparar profissionais que sejam aproveitados nas universidades? Se os juízes buscam nos cursos de especialização uma relação entre a teoria e a prática, parece evidente que há uma lacuna a ser preenchida. Algumas sugestões são dadas e podem ser amadurecidas, como se pode ver mais adiante.

Outro depoimento chama a atenção para a falta de atividades práticas nas aulas. De acordo com essa fala, trata-se de enfocar casos concretos do quotidiano jurídico, por meio do estudo de casos complexos que demandam a aplicação de uma teoria robusta para a sua solução. Em outros termos, as aulas práticas não deveriam se restringir ao exame de situações corriqueiras ou apresentar soluções para casos triviais, mas, ao contrário, deveriam discutir questões em um nível que possibilitasse a abordagem do Direito em uma perspectiva de poder construí-lo a partir da aplicação da lei, ou seja, ver a Ciência Jurídica como poiesis.

[...] em se tratando de um curso de especialização, os temas tratados deveriam ser temas do dia-a-dia, da prática dos juízes e dos alunos [...] a boa prática vem do acabamento de uma boa teoria. Não tem como separar uma da outra [...] tratar do caso concreto, da aplicação da hermenêutica ao caso concreto [...] se preocupar em mostrar para o alunado como as coisas são feitas. (D44)

Ressalte-se, ainda, que este depoimento situa muito bem o entendimento da relação entre teoria e prática, na medida em que é vista numa vinculação dialética e interativa. Os depoimentos dos alunos das turmas de 2001 e 2002 dão a mesma ênfase à falta de atividades práticas durante as aulas, o que mostra a recorrência do problema.

[...] isso varia muito [estudo de casos práticos]. Muitas vezes, depende do professor, apesar de todos serem excelentes, mas vai depender das características do professor. Se ele permite o debate, eventualmente, um ou outro colega traz um caso prático, mas isso não é o norte, não é uma metodologia do todos os professores. (D11) 
Essa diversidade significa que não existe um projeto pedagógico do curso no qual esteja prevista uma adequada divisão da carga horária de trabalho entre as atividades práticas e teóricas. Outra entrevista confirma, de forma mais direta, o que foi dito no depoimento anterior.

[...] o curso, em termos da prática profissional do magistrado, acho que melhorou pouco, poderia ser mais dirigido. Digamos, assim, que houve a preocupação de dar um curso acadêmico, realmente; mas um curso dirigido, para que o juiz venha a vivenciar a sua profissão, não houve. (D20)

Outra opinião comprova a orientação acadêmica do curso, mas não vê problema, uma vez que ela já possui a prática. Nesse caso, a teoria ajuda a prática, mas a sua autora discorda desse tipo de orientação para os cursos dados aos magistrados:

[...] [o curso] é no sentido teórico e a vivência é no sentido prático. Então, a gente era para aplicar o teórico ao prático [no curso] [...] eu acho que se é para a formação de magistrado que vai começar ainda, tem que ver o prático e ligar o teórico ao prático [...] o teórico está dando uma base mais fundamental ao que aprendi sozinha [a prática]. (D09)

Observe-se que a entrevistada D09, no trecho acima, chama a atenção para um fato interessante: a teoria dada nas aulas não ficou fora do contexto de sua formação, uma vez que ela consolidou a prática que já vinham exercendo.

[...] não da forma que eu pensava que haveria integração entre teoria e prática. Achava e ainda penso que os cursos da ESMEC deveriam ter uma matiz diferente daqueles que nós temos na Universidade, porque os cursos de pós-graduação da Universidade são mais voltados para a academia e os da ESMEC deveriam preparar mais para a magistratura; mas, em geral, os professores não tiveram a preocupação em ligar a teoria com a prática, a fim de tornar um curso prático. (D02)

Esses depoimentos reforçam, uma vez mais, a necessidade da realização de um curso mais prático para magistrados que vão iniciar a carreira. Apesar da forma complicada de expressar seu pensamento, a entrevistada observa a posição que o ensino prático deve assumir, nos casos de as turmas serem formadas por magistrados em início de carreira ou que já tenham algum tempo de exercício na magistratura. Segundo ela, aos primeiros devem ser ensinadas as coisas práticas e as teóricas: como proceder no caso de uma Carta Precatória, na condução de um júri popular e na diretiva de uma eleição, por exemplo. No caso dos magistrados mais 
antigos, a teoria deveria servir de embasamento cada vez maior à prática já exercida e aos casos que dela necessitem.

Esses depoimentos criticam, ainda, a orientação didático-científica dos cursos de pós-graduação ministrados pela UFC, e indicam que uma orientação mais prática deveria ser adotada.

Uma comparação entre as visões dos dois entrevistados sugere que alguns alunos foram suficientemente hábeis e aplicaram a teoria dada em suas experiências e vivências, enquanto alguns professores não tiveram a habilidade suficiente para aplicar a teoria aos casos práticos apresentados. Outro depoimento ratifica a opinião do entrevistado (D09), ao afirmar que os professores [...] têm uma vivência teórica, mas para nós que temos a prática combina perfeitamente (D06).

Essa noção de que a teoria ajuda a quem já tem a prática é compartilhada por alguns dos entrevistados. Resumindo, pode-se dizer que a grande maioria dos entrevistados gostaria que uma maior quantidade de horas-aula tivesse sido dedicada às aulas práticas, uma vez que os depoimentos transcritos resumem a mesma opinião de muitos outros entrevistados. Vale ressaltar, mais uma vez, a necessidade de se definir o que se entende por prática. O dia-a-dia corriqueiro do labor jurídico pode trazer alguns problemas, cujas soluções já são conhecidas, bastando, para isso, ter um certo período de vivência profissional. A expressão aulas práticas deve assumir, nesse contexto, uma oportunidade para enfrentar e discutir casos não triviais e polêmicos que demandem o aporte de uma teoria, ou até mesmo a construção de outra, para solucionar aquele caso. Em termos mais específicos, não cabe num curso de pós-graduação discutir minutas de peças jurídicas, embora esse seja um assunto de cunho prático.

\subsection{Utilização, pelos Magistrados, de Conhecimentos sobre Relações Humanas}

A atividade jurisdicional envolve sempre a resolução de conflitos entre partes que não estão dispostas a abrir mão, facilmente, de supostos direitos. Isso coloca o julgador numa posição de mediador e de conciliador de partes conflitantes, no que pese ao seu alto poder de decisão final. $\mathrm{O}$ Estado pode oferecer algumas garantias ao beneficiário de um direito, mas não pode ser efetivo em todas as possíveis ameaças que decorram de decisões judiciais, o que aumenta a importância da adoção de mecanismos de conciliação nos julgamentos de querelas jurídicas. Esse aspecto não tem sido enfocado nos cursos, embora os entrevistados o considerem importante, como aduzem alguns depoentes. 
[...] também não foi tratado esse assunto. Acho que esses assuntos [resolução de conflitos] deveriam ser colocados como parte de um programa de uma disciplina no curso. (D31)

[...] você não vê isso na faculdade, no mestrado e nem no doutorado. No curso da ESMEC que é destinado a magistrados também você não vê esse assunto ser tratado. Todo magistrado, e eu me incluo, tem dificuldade em fazer a transação entre as partes e levar a uma solução do conflito. Então, acho seríssimo e importantíssimo esse assunto. (D26)

É quase certo, portanto, que esse assunto não tenha merecido uma abordagem por parte dos professores, porque a Lei n. 9.099/95 que criou os juizados especiais cíveis e criminais, tendo por objetivo reduzir a burocracia processual e diminuir a morosidade dos julgamentos, trouxe a figura do conciliador, representada por um servidor graduado, com nível superior, cuja missão é receber as reclamações antes do juiz togado e tentar uma composição para que a quizília seja solucionada sem a intervenção do magistrado. Essa modalidade de resolução dos conflitos é o que a lei brasileira apresentou de mais revolucionário nos últimos anos; prova disso é que a comunidade jurídica solicita, reiteradas vezes, através da imprensa, a instalação de mais juizados na comarca de Fortaleza.

As entrevistas citadas apontam lacunas na formação dos magistrados, em áreas como relações humanas, consideradas por eles como importantes para o seu desempenho profissional. Os depoimentos dos alunos dos cursos ministrados em 2001 e 2002 convalidam os anteriores, quanto à inexistência de informações sobre relações humanas, o que é lamentável, haja vista que o juiz trata com as partes nos momentos mais difíceis, como: prisão do filho, marido ou companheiro; separação judicial ou divórcio; abalo patrimonial e outras situações em que o magistrado deveria utilizar conhecimentos sobre relações humanas e Psicologia, por exemplo. Mesmo tendo de encarar certas situações, o magistrado não recebe informação para lidar com elas, conforme depoimento a seguir:

[...] nenhuma atividade relacionada com relações humanas foi desenvolvida. Essa parte aí funciona muito mais se a pessoa tiver sensibilidade, mas em termos de formação, não há nada nos cursos. Eu acho muito importante esse aspecto. Houve apenas uma professora que, informalmente, tocou no assunto, mas por iniciativa própria. (D20)

Apesar da ausência de conteúdos informativos sobre esse assunto, alguns magistrados já trazem, na bagagem pessoal, elementos adquiridos através de leituras ou vivências pessoais, como assegura esse depoente: [...] 
já tinha essa dimensão [relações humanas], estou só aprimorando. Eu adquiri essa dimensão através de leituras pessoais e por experiência própria (D09). A incorporação dessa dimensão ao patrimônio pessoal da depoente teve conseqüências práticas em sua atividade, isto é, não foi algo apenas incorporado intelectualmente. Há um depoimento que enfatiza o uso eficaz das relações humanas no trabalho do dia-a-dia do magistrado.

[...] muitas vezes, essas pessoas precisam ouvir uma palavra amiga. Então, se é necessário abstrair um pouco da técnica para ter aquele contato humano, nós temos procurado fazer isso e nós temos percebido, à luz das estatísticas passadas [da minha comarca], em comparação com as estatísticas presentes, que pela quantidade de acordos que temos conseguido celebrar, notadamente em ações de alimentos, basta um pouco de atenção ao problema social. (D11)

Esse trecho contém um elemento importante que merece ter comprovação verificada por meio de pesquisas empíricas: a humanização da atividade judiciária, obtida por um simples cuidado do juiz no trato com as partes, leva a uma maior quantidade de acordos. Observe-se que a área citada é muito sensível para se conseguir acordo entre as partes envolvidas, pois se trata de decidir sobre algo que envolve a própria sobrevivência da pessoa. A humanização do juiz pode ter outros efeitos sobre o jurisdicionado, como aponta o depoimento a seguir.

[...] quando abro a porta para atender as pessoas que nos procuram, porque estão com problema, com uma doença na alma, que pode atingir o organismo da pessoa, nós, como juízes, poderíamos amenizar e, até, dar uma esperança para aquela pessoa, mostrando a verdade. (D06)

Como se observa, os entrevistados entendem que uma visão humana do magistrado facilita seu trabalho. Depreende-se, dos depoimentos apresentados, que uma visão humana do magistrado não o leva a abrir mão da aplicação justa da lei. Ao ter, porém, uma conversa informal com a parte interessada na decisão, mesmo desfavorável a ela, o juiz pode evitar traumas e problemas dela decorrentes. Além disso, vários depoimentos salientam a importância das relações humanas para o trabalho do juiz.

Falar com as partes deve ser tarefa das mais difíceis para o juiz, uma vez que: a) as partes desejam, sempre, um pronunciamento, ainda que informal, do juiz sobre o mérito da causa, o que pode significar a possibilidade de vitória ou a iminência da perda; b) questionam sempre sobre a atuação profissional do causídico que as acompanha; c) desejam saber o motivo pelo qual a decisão do magistrado foi aquela, 
principalmente se lhe for contrária; d) relatam situações adversas de suas vidas pessoais com o claro objetivo de sensibilizar o juiz. Enfim, é um momento difícil para o magistrado, pois ele, por proibição legal da Lei Orgânica da Magistratura Nacional, e, principalmente, por questões éticas, não pode se pronunciar sobre a causa. Mais uma vez, constata-se a imperiosa necessidade de que a magistratura seja formada por homens e mulheres com maturidade, equilíbrio e seriedade, como se pode constatar no depoimento a seguir.

[...] o serviço judiciário é, digamos assim, em alguns aspectos diferente dos outros, mas em grande parte semelhante a todos os outros. Para executar o serviço deveria haver um curso sobre como tratar e se relacionar com as pessoas que estão necessitando do serviço jurisdicional. (D03)

Como se pode observar, segundo os entrevistados, o tema relações humanas não foi tratado nos cursos objeto deste estudo. Uma das explicações para esse fato é que essa área não faz parte do conteúdo programático do curso. A questão mais geral posta por um dos depoimentos é que, apesar da importância desse assunto para os magistrados, eles não recebem informações a respeito.

\subsection{Inexistência de Conteúdos para a Formação Ética do Magistrado}

Este é outro aspecto não enfocado nos cursos, senão de forma indireta, por iniciativa de alguns professores. Não é de estranhar se isso acontecer, porque os cursos em análise tratam de aspectos específicos do Direito, porém fica uma lacuna na formação dos magistrados. Alguns entrevistados, embora considerem esse aspecto importante, nada disseram sobre esse assunto não ter sido tratado com profundidade, em algum momento de suas carreiras.

[...] esse assunto não foi tratado. Até estranhei, porque acho esse assunto muito importante. É uma falta muito grande não se tratar desse assunto nos cursos. $O$ que sinto aqui no trabalho é que falta muito comportamento ético, principalmente, por parte dos advogados [...] ter informações sobre ética é muito bom e não somente para os advogados. (D21)

Outros depoimentos sugerem que esse tema parece ter sido discutido com base em situações vivenciadas em sala de aula ou fora dela, mas sem uma abordagem profunda e sistemática como um corpo de conhecimentos. 
A questão ética assume, nos dias de hoje, uma importância jamais vista em todas as profissões, mas, na magistratura, é uma questão de sobrevivência da própria instituição. É de se lembrar se não seria o caso de a ESMEC oferecer espaços especiais para isso, quer no momento da admissão do juiz ao Poder Judiciário, quer durante o seu interregno. Malgrado essa constatação, o assunto não tem recebido o tratamento merecido como confirmam esses depoentes, que asseguram: [...] não se discutia [ética] [...] o quanto deveria ser sido discutido. Mesmo assim, o que se discutiu foi de uma forma não sistemática (D31, D21).

Os depoimentos dos alunos dos cursos ministrados confirmam os depoimentos anteriores, quanto à inexistência de informações sobre ética: [...] muito pouco, porque nós não tivemos uma cadeira específica para isso [ética]. Seria muito bom que tivesse uma cadeira pra isso (D09). Outro depoente reforça essa idéia ao assegurar que o que foi visto sobre ética [...] não foi uma coisa voltada para a magistratura, o que poderia ter sido feito (D02).

$\mathrm{O}$ que ocorreu, em algumas disciplinas, foi esse tema ter sido transmitido aos alunos pelo exemplo de vida das pessoas e pelo comportamento dos profissionais da área, como reconhece um depoente: [...] pela própria postura dos juízes, dos professores e o próprio exemplo de vida deles testemunham a sua vivência [da ética] (D06).

Outro entrevistado acrescenta que, em algumas situações, foram lembrados casos de desvio ético, além do exemplo de vida dos professores.

[...] [foram] abordados muitos casos em que o advogado agiu de má fé, de juízes que tiveram também experiências e falam de colegas que não tiveram ética. Nas aulas, são abordados muitos casos e você faz seu juízo de valor. Além disso, todos os professores passam a idéia de ética. (D05)

Vê-se que esse tema não foi tratado de forma profunda e específica, como ocorreu com as relações humanas, pois ele não fazia parte diretamente dos conteúdos ministrados nos cursos. Ou os cursos, objeto do convênio UFC/ESMEC, deveriam ter uma grade curricular diferente? A questão fundamental, reconhecida pelos entrevistados, é que esse assunto, apesar de importante para a formação do magistrado, não recebeu tratamento adequado.

\subsection{Formação Técnica do Magistrado}

A formação técnica do magistrado foi enfocada mais diretamente apenas pelos alunos das turmas que funcionaram em 1995 a 2000. Embora, de modo geral, as entrevistas revelem a aquisição de conteúdos, elas 
indicam, igualmente, que os cursos não apresentaram novidade quanto aos métodos de interpretação e as formas de raciocínio jurídico. Ocorreu sim, em muitos, a descoberta do valor de determinadas disciplinas que eles não haviam percebido durante a graduação, o que não deixa de ser um fato importante sob o ponto de vista de aprendizagem.

Observe-se o trecho a seguir, que mostra a mudança de paradigma de interpretação de sua autora, provocada pelo curso que freqüentou.

[...] as aulas foram dirigidas para nós vivermos o Direito de uma forma aplicada aos princípios constitucionais [...] particularmente, sou muito positivista e houve um destaque para nós deixarmos o positivismo [...] isso foi uma grata surpresa, esse enfoque dado. Houve uma renovação [...] evolui do meu positivismo e isso foi graças ao curso da ESMEC [...] e hoje eu procuro dar esse novo enfoque. (D16)

No caso dessa entrevistada, a mudança foi substancial em termos de procedimento jurídico. Representou uma troca de paradigma de interpretação, algo muito importante em termos de aplicação da lei, pois ela deixou de levar em conta, em seus julgamentos, mais que a letra fria da lei.

Uma entrevistada expressou a revaloração que fez da Hermenêutica Jurídica, disciplina julgada de fundamental importância para o profissional do Direito:

[...] uma matéria interessante foi Hermenêutica. Acho que todo magistrado deveria fazer essa matéria. A própria metodologia dos professores jovens, que aborda os métodos apenas teoricamente, vem enriquecer o nosso dia-a-dia em que aplicamos, na prática, os métodos para interpretar a lei. (D06)

É interessante observar que a entrevistada não faz oposição entre teoria e prática, mas, ao contrário, as formula sob a forma de complementaridade. Para isso acontecer, todavia, ela confirma a necessidade de integração entre a teoria e a prática que devem ser de domínio dos magistrados. Essa compreensão pode explicar por que não tem surgido, até agora, um maior número de críticas sobre o caráter acadêmico dos cursos. Ou será que o encontro desses dois elementos, teoria e prática, dá sempre esse resultado complementar? O trecho a seguir parece confirmar que sim.

[...] eu gosto muito das aulas mais práticas, é evidente, porque nos traz mais subsídios práticos; mas as aulas teóricas que eu não valorizava antes, que eu não valorizava no meu curso de bacharelado, porque não entendia a necessidade delas na prática, hoje é que eu estou vendo a importância delas na prática. (D09) 
A aceitação dessa relação dinâmica entre teoria e prática não exclui a falta de aulas práticas durante o curso, freqüentemente apontada pelos alunos. Isso porque, muitas vezes, eles se defrontam com determinados casos que exigem uma vivência teórico-prática maior, que só uma experiência mais consolidada pode oferecer.

Já foi motivo de observação a importância da atualização e/ou reciclagem na vida funcional dos juízes. Sabe-se que os atos processuais dividem-se em despachos de mero expediente, decisões interlocutórias e sentenças. Os primeiros são aqueles que servem para dar andamento aos feitos, como, por exemplo, remeter os autos ao Tribunal de Justiça do Estado do Ceará, dar vistas às partes e ao Ministério Público; enfim, têm como característica principal o impulso do processo. As decisões interlocutórias são aquelas que exigem maior exercício intelectual do julgador, porquanto devem ser fundamentadas por exigência da Constituição, tais como: apreciação do pedido de liminar, decretação de prisão preventiva, saneamento (correção de eventuais falhas) dos autos, etc. Essas últimas possuem como característica principal alguma mudança em relação ao conflito apresentado, podendo repercutir no próprio direito pleiteado. Sentenças são as decisões que põem fim ao processo; é neste momento que o juiz exerce todo o seu poder jurisdicional, aplicando o Direito aos casos concretos e finalizando o conflito que lhe foi apresentado.

Melhorar a formação técnica do magistrado significa contribuir para que os atos processuais, realizados nos vários processos apreciados diariamente pelos juízes, possam conter o maior número de acertos possíveis, pois não se pode esquecer que o Direito é uma das ciências humanas mais abrangentes e o risco do erro por parte dos magistrados está sempre presente, desde o juiz iniciante até os ministros das mais altas cortes.

Sem dúvida, os entrevistados, ao afirmarem que os cursos de aperfeiçoamento e de especialização proporcionaram uma melhora na qualidade de suas decisões, mostram um fato extremamente importante para o Poder Judiciário cearense. Este motivo é bastante para que a cúpula administrativa devote uma preocupação especial para o aprimoramento constante da atuação da ESMEC, ensejando-lhe todas as condições possíveis para que ela faça parte das prioridades desse Poder. Os depoimentos a seguir exemplificam a aquisição de conhecimentos: [...] houve acréscimo de conhecimentos. Por exemplo, na parte penal, no que diz respeito à medida cautelar (D30). 
[...] especificamente, a turma de 1995 foi muito favorecida porque tinham surgido dois institutos em Processo Civil que estavam ainda em evidência: a Tutela Antecipada e os Juizados Especiais Estaduais. Então, o curso trouxe profissionais que tinham auxiliado a criação dessas leis. Nós pudemos discutir essas leis com esses profissionais. O excelente foi essa oportunidade. (D22)

Quando o entrevistado fez o curso, os conteúdos de Direito Penal e de Direito Civil eram dados ao mesmo tempo. Ao defender a idéia de que o curso deveria tratar mais do Direito substantivo, o entrevistado quer dizer que o curso deveria ter tratado, em seu conteúdo, dos fundamentos do Direito consubstanciados nos códigos cível e penal e não somente nos procedimentos e ritos processuais - o Direito objetivo. Isso porque o direito substantivo, material, é aquele que deve servir para fundamentar o pedido e a contestação na aplicação em casos concretos.

Os assuntos mencionados nos dois depoimentos foram tratados nos chamados Seminários Especiais que faziam parte da grade curricular do curso. Apesar de sua boa aceitação, alguns depoimentos sugerem formas de aperfeiçoar esse recurso: [...] os Seminários Especiais eram muito bons, mas seriam mais proveitosos se os textos das palestras fossem entregues com antecedência para os alunos estudarem (D47).

Outros depoimentos foram genéricos no que diz respeito a algum tipo de acréscimo à formação profissional:

[...] acrescentaram e acrescentam. Eu não consigo imaginar que uma troca de idéias não venha a acrescer nada [...] acresce, porque você convive com pontos de vista os mais diversos, dos colegas que você não conhecia. Acresce, porque você politiza a Magistratura no seu aspecto saudável. Acresce, porque você tem relações sociais [...] você observa momentos os mais diversos, onde colegas se vêem de verdade como um juiz, como um estudante do Direito. Então, acresce. (D27)

No depoimento, o entrevistado cita uma série de acréscimos que o curso ofereceu, mas todos genéricos, haja vista a impossibilidade de quantificar esses acréscimos, embora importantes para a formação do magistrado. De qualquer forma, destacam-se a convivência e o relacionamento social, a oportunidade de uma politização da justiça, o aumento de conhecimentos transmitidos por mecanismos mais amplos que a sala de aula e o retorno à condição de estudante que, para muitos dos depoentes, era uma realidade vivida há algum tempo. Em outro trecho de sua entrevista, ele aponta uma razão de natureza mais substantiva para aquilatar a importância dos cursos de aperfeiçoamento: 
[...] em segundo lugar, havia, naquela época, por parte do Tribunal de Justiça do Estado do Ceará, uma cobrança muito grande em decorrência de uma cultura de que o juiz deveria estar sempre trabalhando muito e no interior. Não era para ele se deslocar para a Capital [...] então, havia uma mentalidade de alguns internos do Tribunal de Justiça do Estado do Ceará, no sentido de que o juiz não poderia estudar. Aquele curso de aperfeiçoamento veio nessa mudança, naquele momento. Então, foram muito importantes a criação e a oferta daquele curso. (D27)

Surge, nesse depoimento, uma certa insatisfação derivada da dificuldade que os magistrados tiveram, durante algum tempo, de poderem se qualificar. A obrigação de fixar residência na comarca é uma exigência constitucional, não cabendo qualquer alegação contrária; mas, se verdadeira, a alegação de que juiz [...] não era para estudar [...], essa sim, merece reflexão. De qualquer forma, o depoimento coloca uma possível política, sobre esse tema, existente no Tribunal de Justiça do Estado do Ceará, em determinada época. Essa opinião deve ser analisada, em razão dos motivos apresentados por alguns depoentes que afirmaram fazer os cursos para poder se afastar das comarcas sem ter problemas com a Corregedoria do Tribunal de Justiça do Estado do Ceará.

$\mathrm{O}$ depoimento a seguir é menos genérico do que o anterior, pois menciona a necessidade de o juiz conhecer não somente as regras do processo, mas também o direito material. É necessário levar em conta o fato de que esses cursos foram freqüentados há alguns anos e, por isso, alguns alunos podem ter esquecido aspectos mais específicos neles abordados.

[...] melhorou. Como todo curso que se faz, sempre há muitos frutos que se colhem. Apenas achei, nessa época, que o curso enfatizava, até de maneira excessiva, a parte de Direito Civil Processual. A grande maioria dos temas tratados envolvia Direito Processual Civil. (D23)

Um entrevistado é taxativo ao afirmar que o curso não contribuiu para a sua vida profissional: [...] mas, num sentido profissional, dizer que contribuiu para que melhorasse meu trabalho, isso não ocorreu (D21).

De qualquer forma, a importância dos Seminários Especiais mencionados fica evidente, pelo menos quanto ao número de horas aulas destinadas pela grade curricular, na medida em que das $420 \mathrm{hs} / \mathrm{a}$ do curso, 105 horas-aula ( $25 \%$ ) eram para essa atividade.

Há depoimentos genéricos sobre a contribuição dos cursos para a formação dos magistrados, como esses que afirmam: [...] os cursos promoveram atualizações (D01), e [...] sem dúvida, porque aprendi coisas que não tinha visto ainda (D14). 
Outros são mais específicos, como atesta o depoente que tem a naturalidade de reconhecer: [...] aprendi determinadas coisas que eu não tinha visto ainda e que me deram mais senso de responsabilidade na minha decisão, por entender os efeitos da minha decisão na sociedade (D09).

Mesmo com a tradição no aspecto didático, as aulas conseguem incutir nos alunos certos valores, como se observa no último depoimento, no qual dois efeitos são indicados: a aquisição de conhecimentos e a compreensão mais ampla do papel desempenhado pelo magistrado na sociedade, em virtude de seu poder de decisão.

Sob o ponto de vista da formação do magistrado, é difícil indicar qual deles é mais importante: se o ensino de conteúdos ou a percepção mais ampla do papel do magistrado. Outro trecho dessa entrevista é mais contundente, pois mostra que o entrevistado não teve apenas uma percepção mais abrangente da responsabilidade do magistrado com a sociedade, mas porque houve uma mudança significativa em sua forma de julgar:

[...] aliás, eu já tinha senso do justo e do injusto. Agora, eu não sabia como fazer para aplicar ao caso concreto, vendo a lei e o sentido do Direito na própria lei, dentro, inserido na própria lei [...] passei de uma interpretação meramente literal, formal, para uma dimensão mais social. (D09)

Decorre da compreensão do texto que o curso ensejou a descoberta da diferença entre a aplicação da lei e a compreensão do que é construir o Direito. Mencione-se, ainda, a idéia da abertura de horizontes em direção ao social, antes referida pela entrevistada.

Não se pode negar que esse é também um dos fatores mais importantes surgidos neste trabalho, pois a função social do juiz é uma das mais relevantes; é ele quem resolve todos os conflitos levados ao Judiciário e, se o julgador tem uma boa visão social do Direito, suas decisões terão uma qualidade infinitamente maior do que aquela meramente técnica.

Veja-se outra mudança no proceder jurídico, em razão do curso, que ocorreu com o autor do depoimento: [...] evoluí do meu positivismo e isso foi graças ao curso da ESMEC [...] hoje eu procuro dar esse enfoque (D16).

Ambos os depoimentos dizem a mesma coisa, com signos semânticos diferentes. Há que se reconhecer, nesse caso, uma percepção intersubjetiva do mesmo efeito operado em dois depoentes. Por outro lado, há depoimentos que apontam para conteúdos bem específicos, que foram aprendidos. 
[...] o curso é muito bom [...] pelas disciplinas que oferece. Eu acho que em 2001, com a Especialização em Processo Civil, eu pude ver disciplinas específicas, e a parte, principalmente, dos Princípios Constitucionais do Processo. Isso aí me motivou muito, porque, em 1995, eu não tinha sido exposta a essa visão do processo, sob o enfoque constitucional. (D16)

Despertar o hábito de estudar e a sair da rotina de trabalho foram outros efeitos do curso, como ocorreu com dois alunos que afirmam: [...] o curso incentiva você a estudar, a pesquisar [...] (D16), e [...] me levou a sair daquele processo, daquele ritmo que o juiz tem de ficar só preso ao estudo dos processos, sem tempo de estudar outra coisa (D06).

É importante observar que hábitos de estudo e pesquisa são fundamentais em qualquer carreira profissional, especialmente em Direito, em que o volume de legislação e de doutrina cresce a cada dia.

Um dos depoentes afirmou que o curso não trouxe qualquer tipo de acréscimo para a sua vida profissional: [...] profissionalmente, não me acrescentou nada. Não existe dentro do curso um programa que você possa usufruir, o contato com os professores é muito superficial, não existe uma bibliografia básica a ser seguida (D03).

Vê-se, claramente, que esse depoente pode ser caracterizado como um caso negativo. Para explicá-lo, fez-se uma análise individual da documentação do entrevistado, a partir da qual ficou esclarecida a razão da sua resposta. A sua formação profissional anterior ao curso mostra que ele ingressou na magistratura após uma extensa carreira profissional, tendo galgado várias conquistas na área do Direito. Ora, não resta dúvida que o nível deste entrevistado é superior à qualificação exigida pelos cursos, o que explica a sua resposta.

Os depoimentos mostraram que os cursos proporcionaram uma variada contribuição para a formação dos magistrados, embora o grau de generalidade de alguns depoimentos não tenha permitido uma melhor aferição dessa contribuição.

\section{REFLEXÕES CONCLUSIVAS}

Os dados empíricos mostrados relevam o lado positivista da fenomenologia. Como é consabido, a fenomenologia não fica nesse estágio da pesquisa. Seu método vai adiante, com a execução da redução eidética e da redução transcendental, o que foi feito na tese.

A utilidade dos dados para as escolas encarregadas da formação de magistrados é inegável. Com efeito, com a aplicação de uma entrevista 
semi-estruturada, foi possível coletar dados com alto nível de comparabilidade e confiabilidade. Praticamente, nenhum aspecto do processo de ensino e aprendizagem ficou fora das análises empreendidas. Os elementos ingredientes do processo de ensino e aprendizagem enfocaram a participação do professor, a metodologia usada em sala de aula, a distribuição dos programas das disciplinas, a contribuição dos cursos para a formação técnica dos magistrados, a convivência em sala de aula, a relação teoria versus prática, e a ausência de conteúdos mais gerais para a formação dos magistrados. Como visto, as falas apontaram contribuições e insuficiências para a formação dos participantes, nesses aspectos.

A tradicionalidade pedagógica, ao lado da falta de relacionamento entre teoria e prática, foi um dos aspectos que mais aproximou esses cursos dos que são ministrados na graduação das Faculdades de Direito.

A boa convivência em sala de aula não foi utilizada como meio pedagógico, apesar de saber que teorias cognitivas apontam esse elemento como fator positivo no processo de aprendizagem (Vigotsky, 2000, 2000a).

Ressalte-se, a propósito, as áreas em que os magistrados julgam que há carências ou nas quais deveriam ser melhor preparados, como Sociologia do Direito, Filosofia do Direito, Ética, Relações Humanas, Epistemologia, o que mostra a visão humanista desses profissionais do Direito.

As deficiências apontadas corroboram estudos de pesquisadores do campo jurídico que já as detectaram, inclusive, nos cursos de graduação em Direito, dentre os quais podem ser mencionados: Bastos (1997), Capella (2000), Dallari (1999), Grinover (1992), Nalini (2001) e Rocha (1992), o que valida os achados deste estudo.

Pelo exposto, é útil e necessário, ao final de um estudo como este, questionar a formação atual de magistrados, bem como a natureza dos cursos que são ofertados para o ingresso na magistratura.

\section{REFERÊNCIAS BIBLIOGRÁFICAS}

BASTOS, Aurélio Wander. O Ensino jurídico no Brasil e as suas personalidades históricas: uma recuperação do seu passado para reconhecer seu futuro. $O A B$ - ensino jurídico: 170 anos de cursos jurídicos no Brasil. Brasília: OAB, Conselho Federal, 1997.

CAPELLA, Juan Ramón. Las Transformaciones de la función del jurista en nuestro tiempo. Revista Crítica Jurídica. Curitiba, Paraná, n.17, 2000. 
DALLARI, Dalmo de Abreu. Deontologia do juiz. Revista Jurídica: órgão nacional de doutrina, jurisprudência, legislação e crítica jurídica, v. 46, n. 255, 1999.

GRINOVER, Ada Pellegrini. Crise e Reforma do Ensino Jurídico. OAB ensino jurídico: diagnóstico, perspectivas e propostas. Brasília: OAB, Conselho Federal, 1992.

HUSSERL, Edmund. A Idéia da fenomenologia. Lisboa: Edições 70, 1990.

. Conferências de Paris. Lisboa: Edições 70, 1992.

Meditações Cartesianas. São Paulo: Madras, 2001.

1950. Idées directrices pour une fenoménologie. Paris: Editions Gallimard,

LEITE, R. H. O Esperado e o obtido na visão dos alunos que freqüentaram os cursos de especialização e aperfeiçoamento da Escola Superior da Magistratura do Ceará (ESMEC), no período de 1995 a 2002. Fortaleza, 2004. Tese (dout.) Faculdade de Educação, Universidade Federal do Ceará.

NALINI, J. R. Ética Geral e Profissional. 3. ed. São Paulo: Editora Revista dos Tribunais, 2001.

ROCHA, Leonel Severo. A Racionalidade Jurídica e o Ensino do Direito. $O A B$ - ensino jurídico: diagnóstico, perspectivas e propostas. Brasília: OAB, Conselho Federal, 1992.

VYGOTSKY, L. S. A Formação social da mente: o desenvolvimento dos processos psicológicos superiores. São Paulo: Martins Fontes, 2000.

Pensamento e linguagem. 2. ed. São Paulo: Martins Fontes, 2000a.

Recebido em: abril 2006

Aprovado para publicação em: agosto 2006 
